\title{
Analysis of Road Accident Hazardous Locations in Bangkhen Police Station, Thailand
}

\author{
A. Leelakajonjit, U. Brannolte, K. Kanitpong, P. Iamtrakul \\ EU-Asia Road Safety Centre of Excellence (RoSCoE) \\ Prince of Songkla University \\ Hat Yai, 90112 Thailand \\ E-mail: amornchai.le@police.go.th, ulrich.brannolte@uni-weimar.de, \\ kanitpon@ait.ac.th, apawinee@hotmail.com
}

\begin{abstract}
A road safety management system needs high quality of accident data to support decision making about accident countermeasures and treatments. As the present road safety management system in most Thai police stations do not use accident data support for hazardous location analysis, this study proposed a better method to identify black spots in Thai police stations. The Bangkhen police station in Bangkok, Thailand was selected as a study area. And, accident data during 2009 - 2011 were collected in this police station. The results from hazardous location analysis found three black spots with a safety potential 538,082 Euro.
\end{abstract}

Keywords: road accident, hazardous location, black spot, Thailand

\section{Introduction}

\subsection{Road safety situation background}

Road traffic accident is an important cause to make Thai citizen death over 10,000 people almost every year [8]. Although the statistics in 2010 show decreasing of fatality number from 10,439 to 7,284 , Thai death rate is still high at 11.40 per 100,000 population and 2.56 per 10,000 registered vehicles. These death numbers are like that there is a war in Thailand.

Thailand has various road accident databases both at official organizations such as Royal Thai Police (RTP), Department of Highways (DoH), Ministry of Public Health, and Department of Disaster Prevention and Mitigation and non-government organizations such as insurant companies, rescue team volunteers and accident research centres of various universities. Each organization develops its database for specific purpose. So, each database has different data structure and quality.

Thailand National Statistical Office surveyed deaths in Thailand 383 thousand are male and 211 thousand are female [6]. Causes of death are classified to 5 majors group of death are non-epidemics, epidemics, accident, decrepit, and others. The majority of 
deaths are non-epidemics 51.4 percentages, decrepit is 25.4 percentages, epidemics 12.7 percentages, accident 7.9 percentages, and others 2.6 percentages.

How useful of accident analysis in preventing the future occurrence of accidents is a fundamental question to people interested in road safety [1]. Normally, the road accident report forms are often $2-4$ pages long or more, which require filling-in at the accident sites, mostly by the pen and paper. During road accident situation, road users affected by the traffic disruption and prohibit the police officers from making detailed and accurate records of all relevant data. Furthermore, the police cannot be regarded as professionals for all information, such as vehicle defects, drivers' state and conditions, and environmental deficiencies [10].

\subsection{Problem statement}

In Thai police stations, police need data to support their road safety works but some of them never analysed the collected data in their station. Some police stations identify hazardous location by their experience and feeling. It will be much better if they analyse accident data for identifying hazardous locations. This study would like to propose a better method to identify the significant hazardous locations.

\section{Objectives and scope of the study}

\subsection{Objective of the study}

This study tries to identify hazardous locations in a police station following these objectives.

- To develop accident database for Thai police stations.

- To improve road hazard identification system for Thailand by developing black spot definition

\subsection{Scope of the study}

This study focuses on road safety management system in Thai police stations. Accident database improvement is limited by these conditions.

(a) The road accident data come from a selected police station.

(b) The accidents happened in 2009 - 2011 only.

(c) The accident data were written in police daily reports.

(d) The accident locations were relocated in Geographic Information System from general descriptions.

\section{Literature review}

Majority of works in this study are involved with a road safety management system. FHWA gave an explanation that Safety Management System (SMS) gives decision makers and those who manage and maintain local roadways the tools to systematically 
identify, prioritize, correct, and evaluate the performance of their transportation safety investments [4].

\subsection{Black spot definition}

"Black Spot" (BS) is a name of hazardous location on the map. Almost all road safety organizations use black spot to present the hazardous locations because black colour refers to poor or bad safety conditions in each location. However, the methodology to identify black spots is variety depend on each country or area supporting factors.

The Institute of Transport Economics, Norway [3] published "State-of-the-art approaches to road accident black spot management and safety analysis of road networks" consists of summarized black spot definitions as following three groups:

1. Numerical definitions
a. Accident number
b. Accident rate
c. Accident rate and number

2. Statistical definitions
a. Critical value of accident number
b. Critical value of accident rate

3. Model-based definitions
a. Empirical Bayes
b. Dispersion value

\subsection{Black spot definition review}

Elvik R. summarized [3] black spot definitions in eight European countries: Austria, Denmark, Flanders of Belgium, Germany, Hungary, Norway, Portugal, and Switzerland.

\subsubsection{Definition of black spot in Austria}

Black spot identification bases on following condition: There are three or more similar injury accidents within 3 years and a relative coefficient $R_{k}$ at least 0.8 .

$$
R_{k}=\frac{U}{0.5+7 \times 10^{-5} \times A A D T}
$$

where:

$\mathrm{AADT}=$ Annual Average Daily Traffic (vehicles/24 hours)

$\mathrm{U} \quad=$ Number of injury accidents within 3 years.

\subsubsection{Definition of black spot in Denmark}

Black spots are considered by comparing with normal number of accidents for a location based on the Poisson distribution. The minimum number of accidents for a site to be considered as black spot is four accidents within five years. 


\subsubsection{Definition of black spot in Flanders of Belgium}

Black spots are identified from score of priority (S) equal 15 or more. The score of priority can be calculated from following formula:

$$
S=L I+3 \times S I+5 \times D I
$$

where:

$\mathrm{LI}=$ total number of slight injuries

$\mathrm{SI}=$ total number of serious injuries

$\mathrm{DI}=$ total number of deadly injuries

Size of a sliding window for black spot identification is 100 meters.

\subsubsection{Definition of black spot in Germany}

Black spots are identified as black if five accidents of similar type have been record within one year at a 100-meter location. For three year period, five or more injury accidents have been recorded or three or more serious injury accidents have been recorded.

\subsubsection{Definition of black spot in Hungary}

In outside build-up area, a black spot is defined as four injury accidents have been recorded during three years within 1,000 meters. For inside build-up area, a black spot is defined as at least four injury accidents have been record during three years on a 100meter road section.

\subsubsection{Definition of black spot in Norway}

There are two types of road hazard locations in Norway. First, a black spot is identified as at least four injury accidents have been recorded within 100 meters during five years. And, a black section is identified as at least 10 injury accidents have been recorded within 1,000-meter road section during five years.

\subsubsection{Definition of black spot in Portugal}

There are two black spot definitions in Portugal. First definition, black spot is 200-meter road section with at least five accidents and severity index greater than 20 during one year. The severity index can be calculated by the following formula

$$
S I=100 \times F A L+10 \times S I+S L
$$

where:

SI $=$ Severity Index

$\mathrm{FAL}=$ total number of fatalities

$\mathrm{SI}=$ total number of serious injuries

$\mathrm{LI}=$ total number of slight injuries

The second definition, an accident prediction model is applied from five year reference period in order to estimate the expected number of accidents. Then, the worst 20 intersections in each road class are selected for detailed accident analysis. 


\subsubsection{Definition of black spot in Switzerland}

Black spots are defined base on the accident rate and critical value for the minimum recorded number of accidents during two years as following conditions. For motorways, the critical accident count values are 10 for all accidents, 4 for injury accidents, and 2 for fatal accidents. For rural roads, the critical values are 8 for all accidents, 4 for injury accidents, and 2 for fatal accidents. For intersections in urban areas, the critical values are 10 for all accidents, 6 for injury accidents, and 2 for fatal accidents. The black spot length is between 100 to 500 meters based on traffic volume.

\section{Methodology}

This study was planned starting with review international and local papers about road hazardous location (black spot) identification. As the second step, the police station was selected as study area based on few accident data conditions. Then accident data were collected for three years period. Third step, the collected data were analysed for appropriate black spot definition. Fourth step, an analysis was conducted on the effectiveness of road traffic enforcement on road safety. Fifth step, some black spot identification methods were selected and applied with collected data in order to produce black spot map for comparison.

\section{Data collection}

This study collected road accident data following the study framework. The collected data from the selected police station were stored in the software developed. Finally, accident data were grouped as accident locations for black spot identification purpose.

\subsection{Selection of study area}

This study selected three police stations to check required data in the pre-data collection process. The police stations were selected from the provinces with the highest number of fatalities in each region in 2011. The numbers of accident involved persons ordering by number of fatalities in 2011 are in Table 1. Nakhorn Ratchasrima province was selected from north east region. Bangkok was selected from central region. Songkla province was selected from south region. The police stations were pre-data collected are Nakhorn Ratchasrima police station in Nkhorn Ratchasrima province north east region, Bang Khen police station in Bangkok central region, and Hat Yai police station in Songkla province south region.

Result of pre-data collection in three police stations found the problems to collect accident data in Nakhorn Ratchasrima police station and Hat Yai police station. So, Bang Khen police station was selected as study area in this study. Bang Khen police station has an area of 40 sq. kilometres, about 350 intersections, 430,000 population, 33 education places, 84 resident communities, 4 ordinary markets, and 5 super markets. 
Table 1. Number of Accident Statistics in 2011 [9]

\begin{tabular}{|c|c|c|c|c|c|c|c|c|}
\hline \multirow[b]{2}{*}{ Order } & \multirow[b]{2}{*}{ Province } & \multicolumn{2}{|c|}{ Fatal Case } & \multicolumn{3}{|c|}{ Injury Case } & \multirow[b]{2}{*}{$\begin{array}{c}\text { Total Acc. } \\
\text { No. }\end{array}$} & \multirow{2}{*}{$\begin{array}{c}\text { Total } \\
\text { Involved } \\
\text { Persons } \\
\end{array}$} \\
\hline & & Acc. No. & $\begin{array}{c}\text { Fatality } \\
\text { No. }\end{array}$ & Acc. No. & $\begin{array}{l}\text { Serious } \\
\text { Injuries }\end{array}$ & $\begin{array}{c}\text { Slight } \\
\text { Injuries }\end{array}$ & & \\
\hline 1 & Bangkok & 373 & 393 & 21,323 & 932 & 23,802 & 21,696 & 25,127 \\
\hline 2 & $\begin{array}{l}\text { Nakorn } \\
\text { Ratchasrima }\end{array}$ & 343 & 369 & 7,600 & 332 & 8,596 & 7,943 & 9,297 \\
\hline 3 & Chonburi & 274 & 286 & 9,774 & 439 & 10,657 & 10,048 & 11,382 \\
\hline 4 & Chengrai & 219 & 241 & 4,795 & 267 & 5,160 & 5,014 & 5,668 \\
\hline 5 & Udonthani & 190 & 219 & 4,123 & 346 & 4,680 & 4,313 & 5,245 \\
\hline 6 & Chengmai & 195 & 208 & 9,906 & 478 & 10,848 & 10,101 & 11,534 \\
\hline 7 & Konkang & 187 & 201 & 3,222 & 146 & 3,619 & 3,409 & 3,966 \\
\hline 8 & Burirum & 182 & 193 & 3,739 & 553 & 3,981 & 3,921 & 4,727 \\
\hline 9 & Rayong & 180 & 193 & 2,802 & 209 & 2,932 & 2,982 & 3,334 \\
\hline 10 & Phetchaburi & 172 & 187 & 4,449 & 106 & 5,348 & 4,621 & 5,641 \\
\hline 11 & Songkla & 158 & 182 & 5,105 & 617 & 5,425 & 5,263 & 6,224 \\
\hline 12 & Nakorn Sawan & 167 & 181 & 5,138 & 99 & 6,036 & 5,305 & 6,316 \\
\hline 13 & \begin{tabular}{|l|} 
Ubon \\
Ratchathani
\end{tabular} & 165 & 178 & 6,520 & 222 & 7,519 & 6,685 & 7,919 \\
\hline 14 & Ayuthaya & 163 & 175 & 2,177 & 111 & 2,463 & 2,340 & 2,749 \\
\hline 15 & $\begin{array}{l}\text { Nahorn } \\
\text { Srithammarat }\end{array}$ & 160 & 167 & 5,369 & 164 & 6,119 & 5,529 & 6,450 \\
\hline
\end{tabular}

\subsection{Data collection procedure}

There are three steps for data collection in this study. First, the police daily reports in 2009 - 2011 were categorized into criminal cases and road accident cases. Second, the road accident daily reports were scanned page by page to digital files because it is not allowed taking them out of the police station. Third, the scanned files were read and input to developed accident database. This step needs to locate the accident locations on the map from descriptive details. Finally, the collected data were ready to be analysed. The data collection procedure is in Figure 1. 


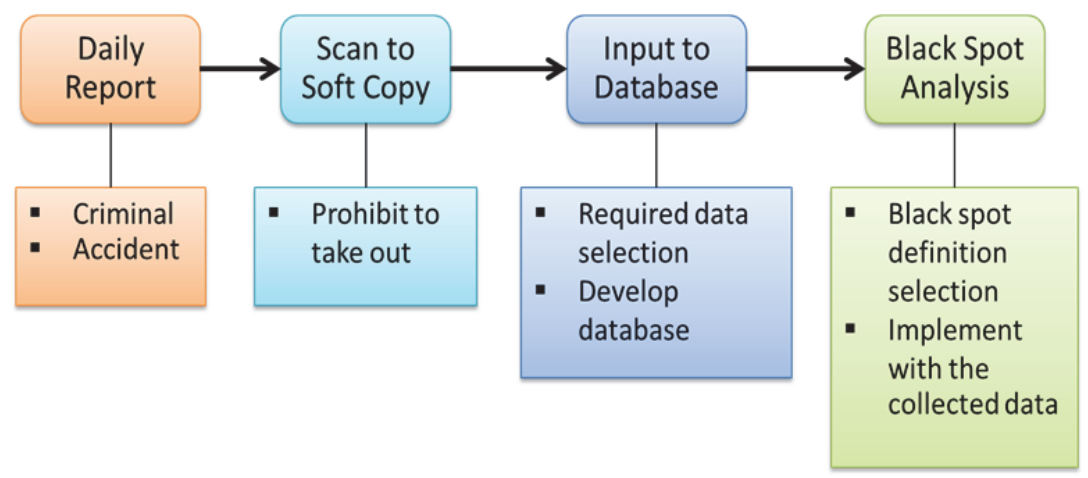

Figure 1. The data collection procedure

\subsection{Software development}

As one of the objectives of this study is to improve accident database, a Road Accident Management System (RAMS) was developed as a model of accident database and used for inputting collected data. This software is also able to group and count accident in the close locations as groups and present accident data in map-based data too. The Figure 2 shows RAMS accident presentation.
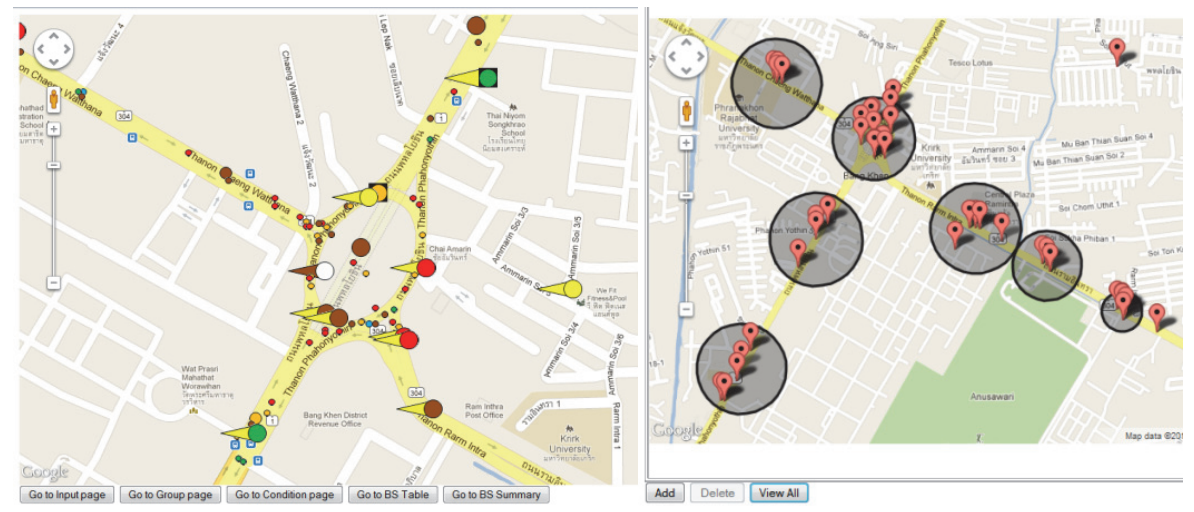

Figure 2. Accident data presentation in RAMS [12]

The collected accident data were categorized by accident severity into fatal accident, serious injury, slight injury, and property damage only (PDO). Accident type of collected data are driving accident, turn off accident, turn in/crossing, crossing over, result from parking, longitudinal accident, and other accident. All the collected data elements for each road accident are 20 variables as in Figure 3. 


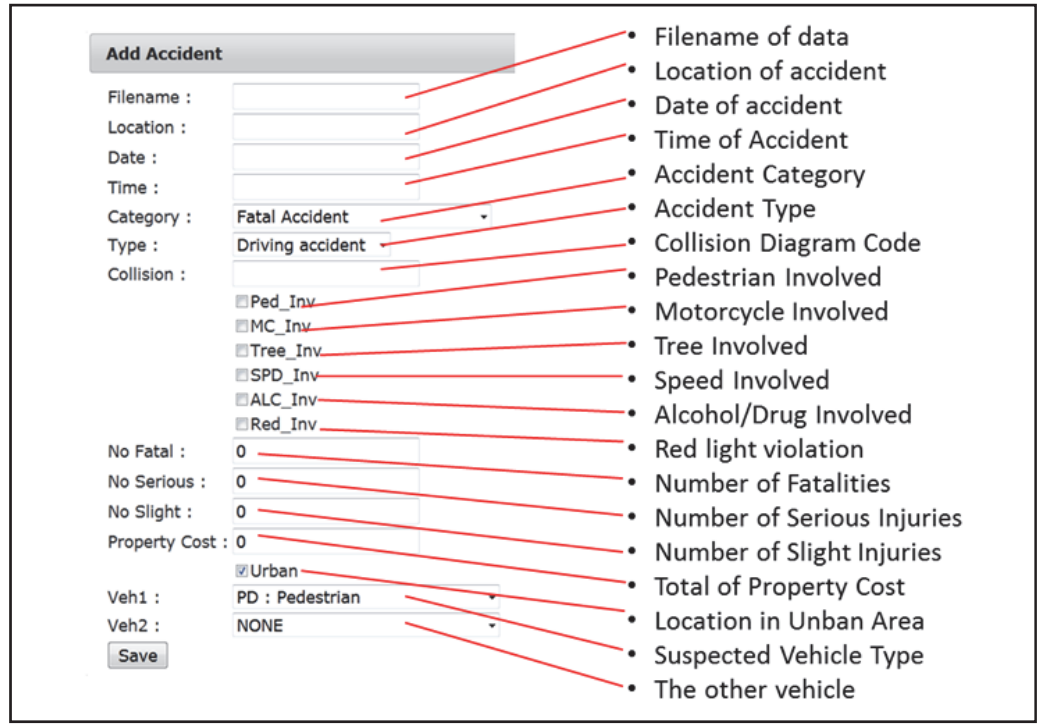

Figure 3. Collected data elements in RAMS

\section{Results of $1^{\text {st }}$ Pilot Study}

\subsection{Scope of 1 st pilot study}

In the $1^{\text {st }}$ pilot study, 40 kilometre square of Bang Khen police station responsible area was narrowed down to an about 9.5 kilometre square study area of $1^{\text {st }}$ pilot study. The $1^{\text {st }}$ pilot study area has about 214 intersections. The two main roads are Ram Intra and Phahonyothin road. A map of this area is in Figure 4.

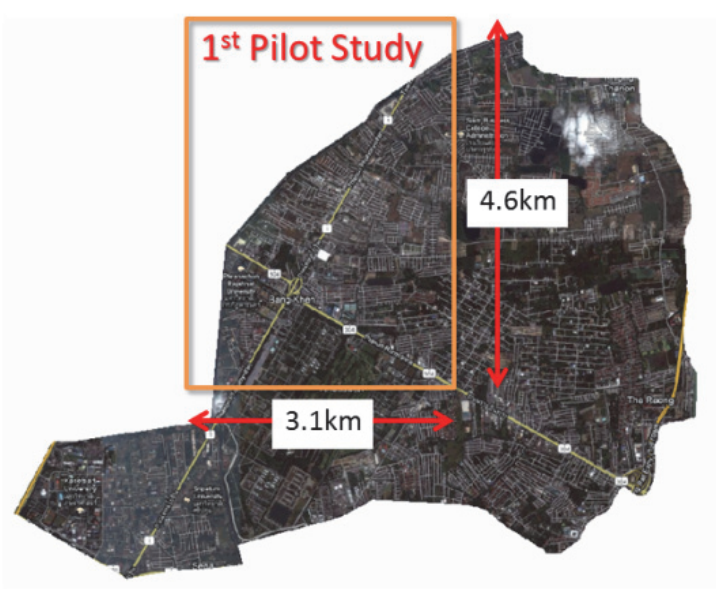

Figure 4. Map of $1^{\text {st }}$ pilot study area 


\subsection{Collected data}

In the $1^{\text {st }}$ pilot study, there are 569 accident happened in $2009-2011$. These accidents can be grouped into 69 locations including some independent locations. The Figure 5 shows collected accident data in RAMS and VISUM Safety. VISUM Safety was developed by PTV [7]. It provides tools for black spot analysis and accident prediction calculation.
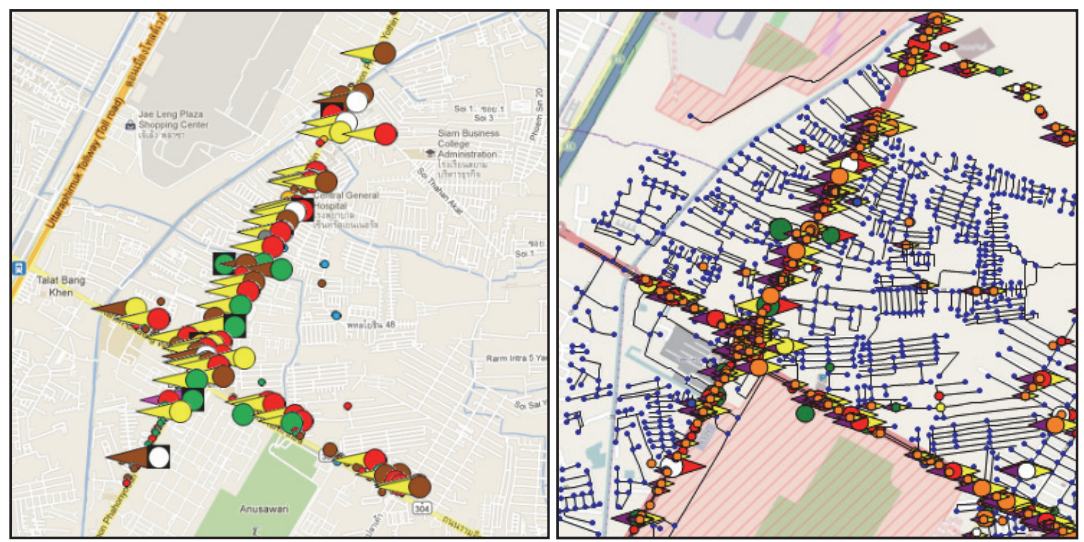

Figure 5. Collected accident locations in RAMS(left) and in VISUM Safety (right)

In $1^{\text {st }}$ pilot study, there are 2 fatalities, 67 serious injuries, and 186 slight injuries. While there are 358 accidents have no injuries. The number of injuries in each accident severity is in Table 2.

Table 2. Number of cases and injuries grouping by accident severity

\begin{tabular}{|c|c|c|}
\hline Severity & Number of cases & Total injuries \\
\hline Fatal Accident & 2 & 2 \\
\hline Serious injury & 55 & 67 \\
\hline Slight injury & 154 & 186 \\
\hline PDO & 358 & - \\
\hline Total & 569 & 255 \\
\hline
\end{tabular}

\subsection{Accident cost}

\subsubsection{Thai Accident Cost in 2012}

Taneerananon P. studied [11] cost of accident and reported accident cost for each accident victim severity as in Table 3 .

As the monetary value is changed depending on inflation rate, the cost of accident severity in 2012 can be calculated by adapting with inflation rate for each year from Bank of Thailand (BOT). The Thailand inflation rates were shown in Table 4. 
Table 3. Cost of accident severity in Thailand [11]

\begin{tabular}{|l|r|r|}
\hline \multicolumn{1}{|c|}{ Severity } & Min (Baht) & \multicolumn{1}{c|}{ Max (Baht) } \\
\hline Fatality(FAL) & $3,959,387$ & $4,658,004$ \\
\hline Disability (DIS) & $4,503,479$ & $5,404,175$ \\
\hline Serious Injury (SI) & 123,245 & 128,836 \\
\hline Slight Injury (SL) & 30,289 & 30,461 \\
\hline Property Damage Only (PDO) & 40,220 & 40,220 \\
\hline
\end{tabular}

Table 4. Inflation rate of Thailand in 2007 - 2011 [2]

\begin{tabular}{|c|c|}
\hline Year & Inflation rate \\
\hline 2007 & 2.3 \\
\hline 2008 & 5.5 \\
\hline 2009 & -0.9 \\
\hline 2010 & 3.3 \\
\hline 2011 & 3.8 \\
\hline
\end{tabular}

This study uses accident cost from the result of adapting inflation rates as in Table 5 for accident cost calculation.

Table 5. Accident cost of accident severity in 2012

\begin{tabular}{|l|c|}
\hline \multicolumn{1}{|c|}{ Severity } & Accident Cost (Baht) \\
\hline Fatality(FAL) & $5,341,943$ \\
\hline Disability (DIS) & $6,197,675$ \\
\hline Serious Injury (SI) & 147,753 \\
\hline Slight Injury (SL) & 34,934 \\
\hline Property Damage Only (PDO) & 46,126 \\
\hline
\end{tabular}

\subsubsection{Average Accident Cost}

As some accidents have multiple severities of injuries, the average accident cost for each accident severity category is needed for accident cost estimation. From the collected data in $1^{\text {st }}$ pilot study, the average accident costs are in Table 6. 
Table 6. Average Accident Cost in $1^{\text {st }}$ pilot study area (Baht)

\begin{tabular}{|l|r|r|r|r|r|r|c|c|}
\hline Severity & $\mathbf{1}$ & $\mathbf{2}$ & $\mathbf{\ldots}$ & $\mathbf{5 6 9}$ & $\Sigma$ & Total cost & Count of Category & Average cost \\
\hline FAL & $\mathrm{xx}$ & $\mathrm{xx}$ & $\mathrm{xx}$ & $\mathrm{xx}$ & 2 & $10,683,887$ & 2 & $5,341,943$ \\
\hline SI & $\mathrm{xx}$ & $\mathrm{xx}$ & $\mathrm{xx}$ & $\mathrm{xx}$ & 69 & $10,194,965$ & 57 & 178,859 \\
\hline SL & $\mathrm{xx}$ & $\mathrm{xx}$ & $\mathrm{xx}$ & $\mathrm{xx}$ & 197 & $6,881,923$ & 162 & 42,481 \\
\hline PDO & $\mathrm{xx}$ & $\mathrm{xx}$ & $\mathrm{xx}$ & $\mathrm{xx}$ & 569 & $26,245,434$ & 348 & 75,418 \\
\hline
\end{tabular}

\subsection{Development of black spot definition}

The average accident cost for each accident severity of collected accidents in the $1^{\text {st }}$ pilot study can be presented by cumulative accident costs for each accident location as in the Figure 6.

Furthermore, black spots should be selected from hazardous locations with a reasonable number. If it is too many, it cannot emphasize the severity in black spot locations. If it too low, it cannot improve the road safety in the area. This study selected the black spots from ranking the accident costs in each location by the cumulative accident cost figures and found two interesting conditions. First, at $5.14 \%$ of the road network (11 locations) occupied $64.84 \%$ of all accident cost in the $1^{\text {st }}$ pilot study. All of the 11 locations probably cannot be treated because of budget limitation of Bang Khen district. Second condition, at $1.40 \%$ of the road network (3 locations) occupied $39.85 \%$ of all accident cost. The number of 3 black spot is more possible to be treated by the road authority. This condition became to be an origin of black spot definition for the $1^{\text {st }}$ pilot study.

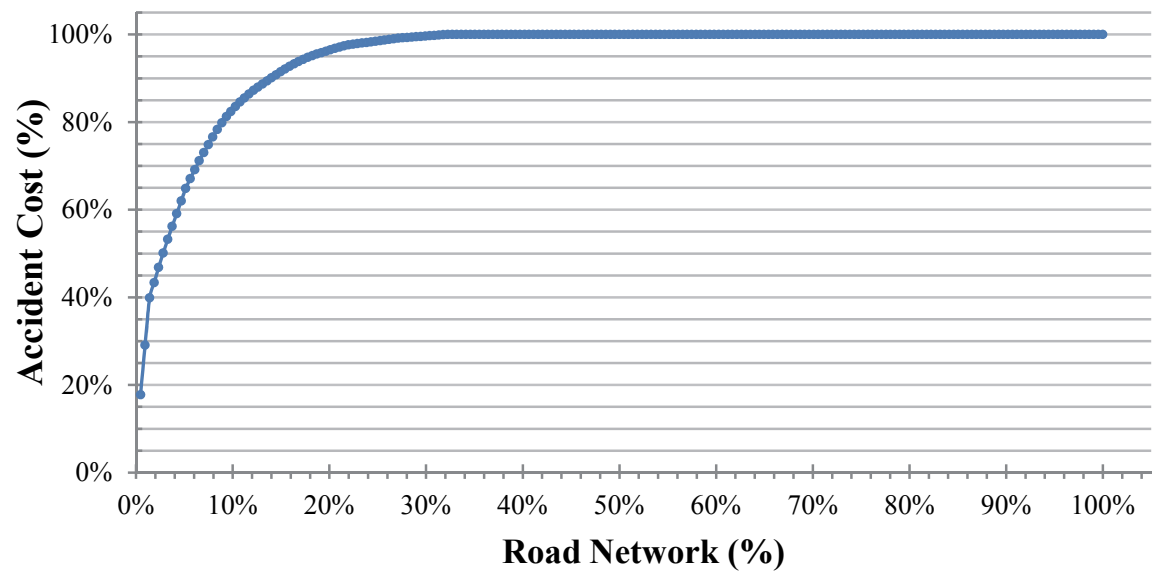

Figure 6. The cumulative accident cost for each accident location in $1^{\text {st }}$ pilot study

The accident figures at the three black spots are 1) 1 fatal accident, 1 serious injury accident, 3 slight injury accidents, 2) 1 fatal accident, 1 serious injury accident, 3) 15 
serious injury accidents, 17 slight injury accidents. The other accident locations have no fatal accidents, the number of serious injury accidents is less than 6 , and number of slight injury accidents is less than 17 . So, the numbers of 1 fatal accident, 6 serious injury accidents, and 17 slight injury accidents were selected to be the black spot definition for the $1^{\text {st }}$ pilot study. The three black spots are shown in Figure 7.

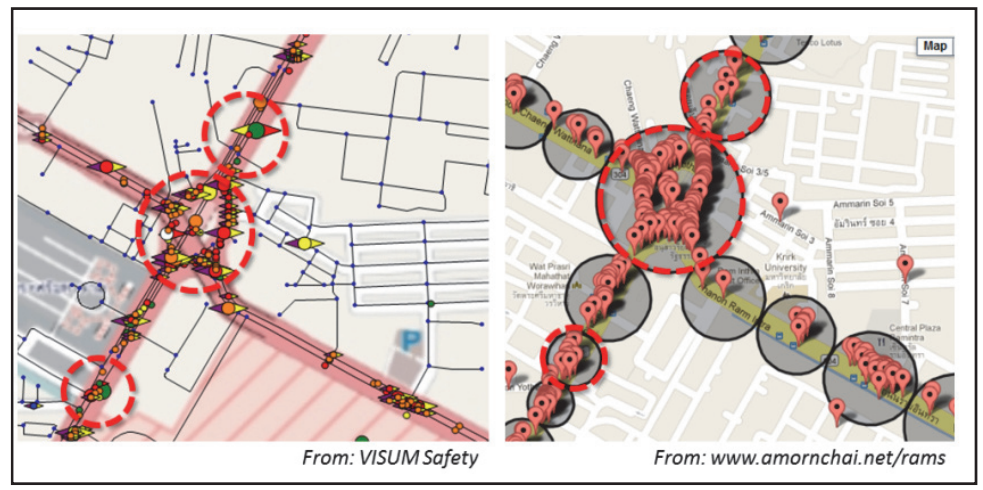

Figure 7. Three black spots from $1^{\text {st }}$ pilot study

\subsection{Safety potential}

The safety potential can be calculated from the difference of the actual accident cost and expected accident cost for a best practice design [5]. In the $1^{\text {st }}$ pilot study, the actual accident cost is 54,006,208 Baht and the expected accident cost for a best treatment is $32,482,930$ Baht. So, the expected safety potential from the black spot definition in the $1^{\text {st }}$ pilot study is $21,523,278$ Baht or 538,082 Euro.

\section{Conclusion and Recommendations}

\subsection{Conclusions}

- The accident number black spot definition is applicable for Thai police stations.

- The road accident database for police data collection is required for road safety management system development in Thailand.

- The model software of the accident database named Road Accident Management System (RAMS) is successfully developed in this study.

- The result of the $1^{\text {st }}$ pilot study data collection in Bang Khen station presents the obvious black spots with 21,523,278 Baht (538,082 Euro) safety potential.

- The accident database can support road safety enforcement in many allegations.

\subsection{Recommendations}

- A road accident database should be implemented in Thai police stations.

- The black spots should be identified by the accident number method.

- The local communities should worry about their safety and implement the proposed black spot management system. 


\section{References}

[1] Loo, B.P.Y.: Validating crash locations for quantitative spatial analysis, Accident Analysis \& Prevention, vol. 38, no. 5, pp. 879-886, 2006

[2] Inflation Rate in Thai Monetary Market, Bank of Thailand, 2012

[3] Sørensen, M., Elvik, R.: State-of-the-art approaches to road accident black spot management and safety analysis of road network, Final report in EC Sixth Framework Programme, Contract N. 506184, 2007

[4] Implementing Local Agency Safety Management, Federal Highway Administration, U.S. Department of Transportation, 2012

[5] Ganneau, F., Lemke, K.: Network Safety Management-from Case Study to Application, 23e congrès mondial de la route Paris 2007: Le choix du développement durable, pp. 1-12, September 17-21, 2007

[6] Summary of Hospital Service Usage of Death Patient in Thailand, National Statistical Office, Thailand, 2006

[7] PTV VISUM Safety User Guide, 2012

[8] Road Accident Statistic, Royal Thai Police, 2012

[9] RVP: Accident Statistics in 2011, Road Accident Victims Protection Company Limited, 2012

[10] Shinar, D., Treat, J.R.: Tri-level Study: Modification Task 3: Validity Assessment of Police-Reported Accident Data, U.S. Department of Transportation, National Highway Traffic Safety Administration, Washington, DC, 1979

[11] Taneerananon, P.: The Study of Traffic Accident Cost in Thailand, Department of Highways, Thailand, 2007

[12] Development of a Road Safety Management Systems for Thailand on the Basis of Improved Accident Database, www.amornchai.net/rams/, visited at 04/04/2013 